\title{
Devolution of Early Childhood Development and \\ Education in Kenya: Improvement in the Status of \\ Infrastructural Facilities and Its Influence on Enrolment in Siaya County
}

\author{
Odundo Amollo Paul (Corresponding author) \\ Department of Educational Communication and Technology, University of Nairobi, \\ P.O BOX 30197-00100 Nairobi, Kenya \\ Email: odundopaul@yahoo.com
}

Received: May 28, 2018

Accepted: June 15, 2018

Published: August 20, 2018

doi:10.5296/jet.v5i2.13614

URL: http://dx.doi.org/10.5296/jet.v5i2.13614

\begin{abstract}
The Kenyan Constitution devolves to County governments the responsibility to deliver quality Early Childhood Development and Education (ECDE) services. This study focused on determining infrastructural facilities that influenced ECDE enrolment during the first three years of devolution, viz. 2013/14, 2014/15 and 2015/16. Its purpose was influence County Government's investment decisions in ECDE infrastructural facilities, as well as contribute to relevant policy discourses and stimulate research in developing countries. Quantitative data were sourced from 145 participants, including education officers, administrators and teachers; while qualitative data were obtained from 12 participants including senior education officers, non-governmental agencies and head teachers of primary schools hosting ECDE centres. Results show that the extent of increase in ECDE enrolment significantly associated with improvement in the status of classrooms $\left(\chi^{2}=30.453, \mathrm{df}=8 \& \rho\right.$-value $\left.=0.000\right)$; and furniture $\left(\chi^{2}=25.938, \mathrm{df}=8 \& \rho\right.$-value $\left.=0.001\right)$. However, no significant association existed between the extent of increase in ECDE enrolment and improvement in the status of: sanitation facilities $\left(\chi^{2}=3.057, \mathrm{df}=8 \& \rho\right.$-value $\left.=0.931\right)$; outdoor play equipment $\left(\chi^{2}=1.609, \mathrm{df}=6 \& \rho\right.$-value $=$ $0.925)$; as well as assistive facilities $\left(\chi^{2}=2.840\right.$, $\mathrm{df}=6 \& \rho$-value $\left.=0.829\right)$. Of the five infrastructural facilities, only classrooms and furniture improved to the extent of causing a significant influence on enrolment. The results amplify the need for the County Government to broaden the scope of infrastructural facilities considered in the investment plan for public ECDE centres to provide holistic development to children; thereby, build a strong foundation for lifelong educational attainment and socio-economic development.
\end{abstract}

Keywords: Devolution, Early Childhood Development, Infrastructural facilities, Enrolment level 


\section{Introduction}

Devolution is a genre of decentralisation that involves large-scale transfer of political, administrative, as well as fiscal authority and responsibility from national to sub-national governments for a range of public functions (World Bank, 2015). Kenya's Constitution, which was promulgated in 2010, creates a devolved governance system involving one national and 47 county governments, as listed in the First Schedule. The purpose of Kenya's devolution is to promote social and economic development by improving delivery of proximate services, among other objects outlined in Article 174 (a-i). The Fourth Schedule of the Constitution distributes functions and powers between the national and County governments. Part 2 of the Schedule, read together with Section 5 of the County Governments Act, 2012, elucidates specific mandates of county governments. More specifically, Part 2(9) of the Fourth Schedule confers to County governments the responsibility to provide pre-primary education and childcare services. Such services are collectively encapsulated in the phrase Early Childhood Development and Education (ECDE), which is the holistic development of a child's social, emotional, cognitive, linguistic and physical needs in order to build a solid and broad foundation for lifelong learning and wellbeing (United Nations Educational, Scientific and Cultural Organisation [UNESCO], 2010). The devolution of ECDE to County governments resonates with Section 26(1) of the Basic Education Act No. 14 of 2013, which further elucidates that County governments are responsible for funding the development of required infrastructure for institutions providing ECDE services (Shinali \& Kamau, 2016; Government of Kenya [GoK], 2010; 2013; Garcia \& Neuman, 2010).

In view of this, County governments are expected to act within the confines of the national ECDE Policy Framework, which provides important guidelines for coordinating ECDE programmes across sectors to ensure that holistic needs of young children are met to enable them fulfil their potential (GoK, 2006a). More specifically, the National Policy Framework underscores the importance of ECDE, as one of the most important levers for accelerating the attainment of Education for All goals, as well as Millennium Development Goals (MDGs), which have since transitioned to Sustainable Development Goals (SDGs) (UNESCO, 2017; Shinali \& Kamau, 2016; GoK, 2006a). The National Policy Framework further recognises the importance of stakeholders in expanding opportunities for young children to access ECDE services, as well as the importance of paying attention to the needs of vulnerable groups such as those living with disability. The Policy Framework is operationalised through the ECDE Service Standard Guidelines for Kenya, which ensures that all service providers, including parents, communities, governments and non-government agencies as well as the private sector, provide quality, accessible and equitable services for young children (GoK, 2006b). In relation to infrastructural facilities, the Service Standard Guidelines specify minimum standards for establishing ECDE centres, constructing and furnishing classrooms, as well as for developing appropriate sanitation, water, outdoor play and assistive facilities for children with disability. The ultimate goal of the Service Standard Guidelines is to improve access and ensure $100 \%$ enrolment by all eligible children (GoK, 2006b). 
A review of extant statistical literature reveals that in Kenya, ECDE Net Enrolment Rate (NER), has increased steadily from about $34 \%$ in 2006 to 50\% in 2009; and further to $75 \%$ in 2015 (GoK, 2016; 2012a). However, the national picture blankets significant variations across counties, with about $60 \%$ of the counties having NERs below the national average. In Siaya County, recent data show that NER has increased gradually from 28\% in 2006 to $47 \%$ in 2009 and further to $66 \%$ in 2015, which was lower than the MDG target of $80 \%$ access by 2015. This implies that about $34 \%$ of children aged 3 to 5 years were not accessing ECDE services (County Government of Siaya, 2016). Extant policy literature attributes sub-optimal ECDE enrolment across the country to various factors including; inadequate number of centres, insufficient number of trained teachers and caregivers; inadequate teaching, learning and play equipment, limited community participation, low morale of teaching staff due to poor remuneration, limited enforcement of standards within the centres, inadequate nutrition and health support services; as well as inadequacy of essential infrastructural facilities (County Government of Siaya, 2016; GoK, 2016).

When County governments assumed the constitutional responsibility of providing ECDE, they focused on addressing the cited challenges in order to enhance access, in line with requirements of the Policy Framework (Shinali \& Kamau, 2016; GoK, 2006a). In this regard, County governments have dwelt on creating funding modalities for ECDE to include start-up grants, capitation grants, instructional materials, school feeding, maintenance and development of infrastructural facilities (Shinali \& Kamau, 2016). In Siaya County, the Government initiated a four-pronged strategy to improve access to quality ECDE, focusing on increasing enrolment, enhancing curriculum implementation, improving nutrition of learners and strengthening the management of ECDE centres (County Government of Siaya, 2014). To increase enrolment, the County Government prioritised construction of new ECDE centres, following one standard design, including three classrooms, an office and a store. ECDE projects are proposed by citizens during public participation forums, in line with section 115(1) of the County Governments Act (GoK, 2012b); and prioritised according to approved budgets and availability of finances. At the time of this study, the County Government had spent about KES 120 million in constructing and furnishing new centres, most of which are domiciled in primary schools; as well as improving and equipping old ones, in accordance with guidelines of the national Policy Framework (GoK, 2016; 2006a).

Empirical studies conducted in various contexts have found that improvement of basic infrastructural facilities has a significant correlation with increase in ECDE enrolment levels. For instance, a study commissioned by the United States Agency for International Development (USAID) in multiple developing countries reported that distance covered by children from home to ECDE centres significantly affected enrolment levels. More specifically, the study demonstrated that for every additional kilometre that a child travels between home and school, attendance drops by $20 \%$ or more. Based on this, the study amplified the need for stakeholders to establish new centres and improve existing ones, in order to reduce distance covered by children, which would improve enrolment as well as sustain attendance. The linkage between status of ECDE infrastructural facilities and variation in enrolment levels has been examined, both descriptively and inferentially, by a 
number of other studies, including (Kang'ethe, Wakahiu and Karanja 2015; Osho, Aliyu, Okolie and Onifade 2014; Van der Gaag and Putcha 2013; Wanjau (2013); as well as Jasper, Le and Bartram 2012), among others.

This study examined the relationship between basic infrastructural facilities and ECDE enrolment, based on the perspective of key stakeholders including senior education officers, ECDE coordinators, teachers, head teachers of host primary schools, sub-county administrators, as well as ward and village administrators. Indirectly, the study appraised performance of the County Government in improving infrastructural facilities as a precursor to stimulating enrolment. It was motivated by the dearth of academic literature on how devolved governance system was tackling issues related to infrastructural facilities in line with the National Policy Framework and Service Standards Guidelines, in order to improve enrolment and accessibility of ECDE services.

The subject of this study was worthy the investigation because ECDE provides an important foundation for lifelong educational attainment for all, which is an indispensible antecedent for personal and national socio-economic development (UNESCO, 2017; 2010). Universal or near-universal enrolment rate for ECDE is vital for laying down a strong foundation for national development (GoK, 2006b). By informing education stakeholders, the study findings were expected to stimulate actions for improving not only enrolment, but also the quality of services provided by ECDE centres. The study was expected to yield information that would influence the County Government's investment decisions in ECDE in order to address learners' essential needs and improve enrolment. The study was also expected to contribute to relevant policy discourses and stimulate research in Kenya and other developing countries.

\section{Literature Review}

Early childhood is an important period of brain development that has a significant influence on an individual's personality, intelligence, health, attitudes and aptitude for learning as well as behaviour throughout life (UNESCO, 2010; Garcia \& Neuman, 2010). Whereas developed countries consider early childhood to be the period from birth to eight years; in most developing countries, childhood period ranges from birth to six years (United Nations Children's Fund [UNICEF], 2008). Regardless of variations in definitions, early childhood provides a crucial opportunity for appropriate interventions aimed at improving educational attainment, socio-economic status and human development indices (UNESCO, 2010; UNICEF, 2008). Appropriate ECDE is recognised globally as an important intervention in the life of children, aimed at promoting optimal and holistic brain development for proper learning in later stages (UNESCO, 2010). In this regard, (Chepkonga 2017) points out that quality of the learning environment is a critical determinant of the extent to which a child's brain develops. Quality of the learning environment is defined by the status of basic infrastructural facilities and resources (Garcia \& Neuman, 2010). For instance, availability and adequacy of basic infrastructural facilities forms the core of UNICEF's child-friendly ECDE model, which aims at improving quality, enrolment and accessibility of appropriate services in developing countries (UNICEF, 2009). 
Existing policy and empirical literature reveal that status of infrastructural facilities such as classrooms, sanitation, play equipment, as well as assistive facilities for learners with disability, are key factors that influence ECDE enrolment levels across developing countries (GoK, 2016; Mawere \& Muguti, 2015; Wanjau, 2013; Alexander, Dreibelbis, Freeman, Ojeny \& Rheingans, 2013; Jasper et al., 2012; Nebraska Department of Education [NDE], 2011, among others). For instance, the policy guidelines published by NDE recognise the importance of ECDE centres having adequate classrooms as a fundamental requirement for children's cognitive and social development (NDE, 2011). The guidelines delve into essential qualities of an ideal classroom for ECDE children, including how spaces for various activities such as creative art, reading, play, sleeping and storage, should be organised. Internal organisation of ECDE classrooms helps children to explore, discover, experiment with, imitate and manipulate age appropriate materials, which in turn, creates a sense of belonging; thus, making the space attractive to children (NDE, 2011). Even though the NDE guidelines describe qualities of an ideal classroom for ECDE children, it does not expressly connect the status of such facilities with changes in enrolment level.

In Zimbabwe, (Mawere and Muguti 2015) reported that in most ECDE centres, (79\%), classrooms were inadequate for the learner population; while in about two-thirds, classrooms were unsuitable for use by young children, considering the poor state of floors, walls, roofs and ventilations. However, the study was purely descriptive; hence, it did not determine the statistical relationship between the status of such facilities with changes in enrolment level. Earlier, (Wanjau 2013) identified inadequacy of classrooms as a key factor contributing to sub-optimal enrolment in public ECDE centres, most of which were established within primary schools. The study found that some centres relinquished their classrooms for use by primary school pupils; thus, leaving multi-grade learners congested in a room or two. Such congestion set a conducive precedence for recurrent infections, inconsistent attendance and sub-optimal enrolment (Wanjau, 2013). Notably though, the study's design did not involve determination of the statistical relationship between status of classrooms and variations in enrolment level.

The type of furniture provided in ECDE centres has significant implications on learners' safety, comfort, physical development and learning achievement. This assertion was confirmed by (Mawere and Muguti 2015) whose study reported that more than two-thirds of ECDE centres lacked adequate furniture, while most of the available chairs and desks were unsuitable and unsafe for use by young children. Similarly, (Osho et al. 2014) found that only one-third of the centres involved in their study, had chairs and desks that were appropriate for use by ECDE children. Lack of age appropriate furniture exposed children to soil-related infections, which affected enrolment through absenteeism. In their study, (Kang'ethe et al. 2015) found that in public ECDE centres, children sat on desks that were designed for children of primary school age, which increased discomfort and risk of falling down. In this regard, shortage of appropriate seats was cited as one of the factors preventing parents from enrolling their children in public ECDE centres. Inadequacy of furniture suitable for children was also identified by (Wanjau 2013) as one of the factors inhibiting ECDE enrolment. A common feature of the cited studies is that they relied on descriptive and/or qualitative 
methods to examine furniture-related challenges in ECDE centres. None attempted to determine the statistical relationship between such challenges and enrolment levels.

Access to appropriate sanitation facilities is important for preventing infections as well as encouraging enrolment. A number of studies have examined linkages between access to sanitation facilities and ECDE enrolment levels. For instance, (Jasper et al., 2012) noted that inadequate access to appropriate sanitation facilities in ECDE centres affected enrolment by heightening the risk of adverse health outcomes among children, including infectious, gastrointestinal, neuro-cognitive and psychological illnesses. Similarly, (Alexander et al., 2013) found that poor sanitation conditions affected children's health status, which in turn, reduced educational outcomes by contributing to absenteeism and impairing cognitive abilities. Similar findings were reported by (Adukia 2013) who demonstrated that access to suitable toilet facilities influenced more parents to enrol their children in public schools. Notably though, the study's focus was general to all educational institutions; thus, it fails to bring out linkage between the two aspects within the context of ECDE centres. Further, (Van der Gaag and Putcha 2013) also reported a connection between access to appropriate sanitation facilities in school and attendance. The study reported that status of sanitation facilities, which was measured in terms of availability, suitability and safety, is a primary factor that influences parents' choice of schools for their children. On their part, (Jordanova, Cronk, Obando, Medina, Kinoshita and Bartram 2015) took a different route by comparing access to appropriate sanitation facilities in schools between developed and developing countries. A striking conclusion from the study posits that benefits associated with access to appropriate sanitation facilities in schools, including universal enrolment and learning consistency, were yet to be realised in most developing countries.

Furthermore, existing literature distinguishes between availability and suitability of sanitation facilities. For instance, (Mawere and Muguti 2015) observed that even though toilet facilities were adequate in about three-quarters of ECDE centres, $85 \%$ of the facilities were unsuitable for use by younger children. The authors noted that in most centres located in primary schools, younger children shared toilets with their older colleagues of primary sections, a situation which heightened the risk of infections. Similar findings were published by (Chepkonga 2017), who noted that pupils in primary schools shared toilets with ECDE children. Like (Mawere and Muguti 2015 and Chepkonga 2017) linked sharing of toilet facilities with increasing incidences of sanitation-related ailments among ECDE children. Heavy infestation by intestinal worms is the most common sanitation-related ailment, which affects children's physical and intellectual development, and compels them to skip school (Burgers, 2000). Moreover, (Burgers 2000) brings out a unique perspective regarding the relationship between sanitation facilities and enrolment by noting that where such facilities are available, they are not adapted to the needs of children with disability; thereby, affecting their enrolment.

Outdoor play equipment are important components of ECDE that children need for cognitive development and social interaction (NDE, 2011). Similarly, (McCarthy and Guiney 2004) note that outdoor play equipment enables pupils to develop physical, cognitive and social well-being. Further, (Johnson, Christie and Wardle 2010) observe that outdoor play enables 
ECDE children to develop by exploring, taking-risks, improving motor skills and absorbing basic knowledge. In this regard, outdoor play is a crucial component in the growth and development of brain, body and intellect. Earlier, (Gallahue 1993) provides a comprehensive discussion of the motor skills development and movement skill acquisition by young children, which must be encouraged in outdoor playgrounds. Quality ECDE should incorporate sufficient facilities to enable holistic development of children. Nonetheless, the study published by (KENPRO 2014), identifies inadequacy of outdoor play equipment as a key factor that influence parents' choices of ECDE centres. Similar findings were reiterated by (Kang'ethe et al. 2015), who identified lack of outdoor fixed play equipment as a key factor denying children quality ECDE services. Notably though, none of the cited literature is explicit about the relationship between status of outdoor play equipment and enrolment in public ECDE centres.

Assistive facilities are important for facilitating enrolment and participation of children with disability in curricular and co-curricular activities. Studies conducted in various contexts have examined the dyadic relationship between availability of assistive infrastructural facilities in educational institutions and enrolment of children with disability. For instance, (Stubbs 2009) identified lack of appropriate assistive resources as a key barrier to enrolment for inclusive education in developing countries. The author underscored the importance physical access to school and various buildings within school as an essential prerequisite for enrolment of children with disability. Similarly, a monitoring report compiled by UNESCO found a significant relationship between distance to school and enrolment of children with physical forms of disability. Within schools, participation of such children in learning and co-curricular activities was constrained by issues such as steep stairs, narrow doorways, inappropriate seating, as well as inaccessible sanitation facilities (UNESCO, 2010). In the United States, (Chambers, Shkolnik \& Pérez 2003) found that the average cost of educating a child with disability was about 1.9 times the cost of educating a regular child, with the odds ratios ranging from 1.6 to 3.1 depending on the type and extent of disability. The findings were attributed to the high cost of modifying physical facilities to facilitate access by children with disability, as well as procurement of essential equipment. In developing countries, the high cost of preparing assistive facilities for inclusive education is one factor that affects the enrolment of children with disability (Chambers et al., 2003).

In Kenya, the linkage between assistive infrastructural facilities and enrolment of children with disability is an issue that feature in policy literature. For instance, the Policy Framework for Education underscores the importance of assistive facilities in reducing effects of disabilities by enhancing functionality and mobility of disabled learners at all tiers of education system. However, it identifies the inadequacy of appropriate assistive facilities as a primary factor constraining enrolment of such learners (GoK, 2012). In This regard, the Policy Framework for Education prioritises the need for educational institutions to modify and adapt infrastructural facilities in order to facilitate mobility and participation of children with disability (GoK, 2012). Notably though, the subject has not received as much attention in empirical studies. Of the reviewed empirical literature, only (Kang'ethe et al.(2015) linked sub-optimal enrolment of children with disability in public ECDE centres to lack of assistive 
facilities such as rumps, rails and lower door handles.

Nonetheless, the cited pieces of literature suggest that there is a correlational linkage between various basic infrastructural facilities and ECDE enrolment level and retention. This study focused on examining the influence of five such facilities and enrolment level. Figure 1 shows the hypothesised relationship between infrastructural facilities selected for this study and ECDE enrolment level.

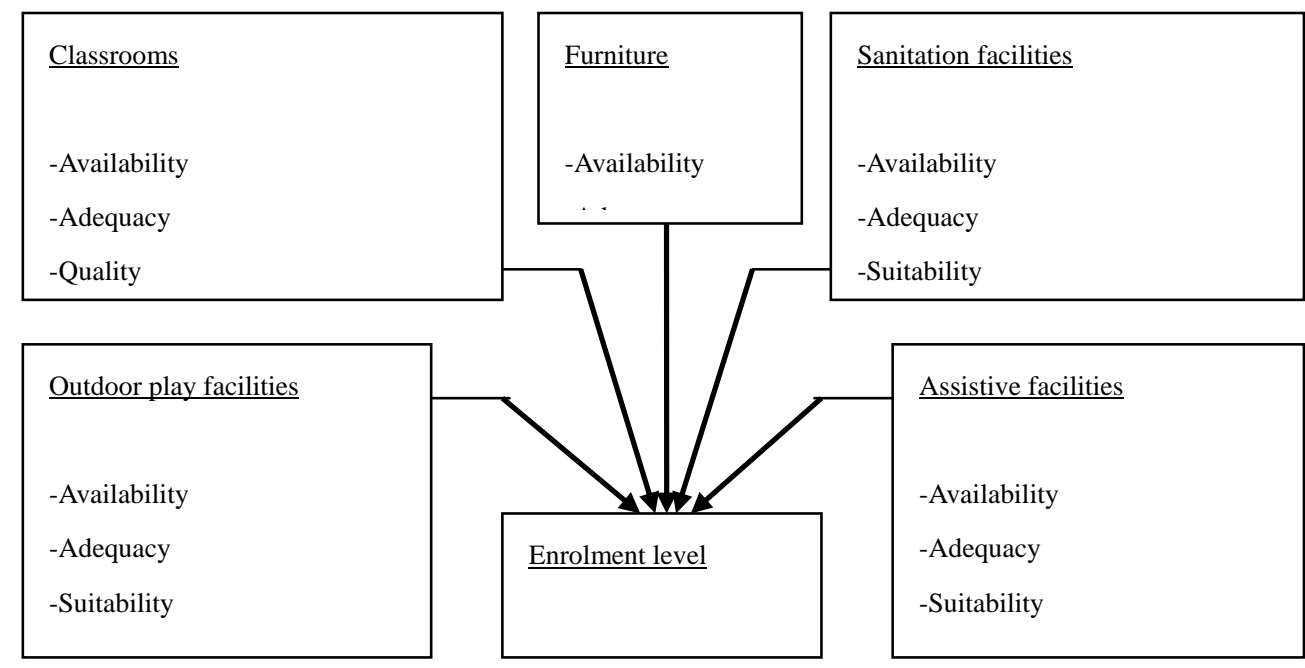

Figure 1. Hypothesised relationship between infrastructural facilities and ECDE enrolment level

As indicated in Figure 1, the study covered five basic infrastructural facilities including classrooms, furniture, sanitation facilities, outdoor play equipment, as well as assistive facilities for learners with disability. More specifically, the terms 'sanitation facilities' included toilets and hand washing systems, while 'assistive facilities' included rumps, wheelchair passages, low blackboards, rails and other equipment used by learners with physical disability. The main aspects of the facilities that feature in the cited literature are availability, adequacy, quality, suitability and safety. In this study, these aspects were encapsulated in the term 'status'. Consequently, participants were asked to consider all the stated aspects before providing an overall view regarding improvement in the status of each infrastructural facility over the preceding three years of devolution, viz. 2013/14, 2014/15 and $2015 / 16$. Similarly, enrolment level was operationalised in terms of perceived extent to which it had increased over the reference period.

\section{Methods}

The methodological approaches adopted by the study are founded on two antonymic but complementary philosophical schools of thought, namely, positivism and constructivism. Ontologically, the positivist school of thought holds that information derived objectively from sensory experience with phenomena is the exclusive source of all authoritative knowledge, provided that the phenomenon in question and the researcher are mutually independent. 
Contrastingly, the constructivist school of thought believes that phenomena are socially constructed and are subjectively observed, which implies that constructivist researchers are part of the phenomenon being observed. Epistemologically, whereas positivist scholars reduce phenomenon to simple measurable variables, test null hypotheses and focus on determining causality; constructivists focus on the meaning of reality being observed in order to understand dynamics and patterns of reality from within and without, and induce generalisations. Methodologically, positivist scholars apply quantitative survey procedures to capture data for descriptive and inferential purposes, while constructivist scholars source information through qualitative methods such as Key Informant Interviews (KIIs), Focused Group Discussions (FGDs) and observation, among other methods (Wong, 2014; Ashley \& Orenstein, 2005; Sale, Lohfeld \& Brazil, 2002; Hughes \& Sharrock, 1997).

The study targeted education and administrative officers as well as teachers, who were involved in provision of ECDE services, through actions such as policy formulation, planning, funding, supervision, monitoring and reporting, as well as actual delivery of services. A review of County Government documents reveals that targeted participants were about 585; a figure which was designated population from where a sample size was drawn. The investigator then applied Fisher's formula for determining samples from finite populations, which states that: -

$$
n_{0}=\frac{p(1-p)}{\left[\left(\frac{a}{z}\right)^{2}+p(1-p) / N_{0}\right]}=\frac{0.5(1-0.5)}{\left[\left(\frac{0.05}{1.96}\right)^{2}+0.5(1-0.5) / 585\right]}=232
$$

Where: $\mathrm{n}_{0}=$ sample size, $\mathrm{N}_{0}=$ population, $\mathrm{p}=$ estimated population variance: $0.5, \alpha=$ desired precision: $0.05, \mathrm{Z}=$ confidence level: 1.96 for $95 \%$ on the normal distribution curve (Fink, 1995). The formula obtained a sample size of 232 participants, which was corrected for design effects using the formula: -

$$
n_{i}=\frac{n_{0}}{1+\left(n_{0} / N_{0}\right)}=\frac{232}{1+(232 / 585)}=166
$$

Where $n_{i}=$ corrected sample size, $\mathrm{n}_{0}=$ computed sample size: $232, \mathrm{~N}_{0}=$ population: 585 . The correction process obtained a final sample size of 166 participants, which again, was divided proportionately between the various categories of participants, using the formula stated below.

$n_{c}=\left(n_{i} / N_{0}\right) * N_{c}$

Where $n_{c}=$ sample size for each category of participants; $n_{i}=$ corrected sample size (166); $N_{c}$ = population (585); $\mathrm{n}_{\mathrm{i}} / \mathrm{N}_{0}=$ the sampling fraction (0.284006); and $\mathrm{N}_{\mathrm{c}}=$ population for each category of participants. The computations obtained the results indicated in Table 1. The last column of the Table shows the actualised sample size. 
Table 1. Distribution of the sample sizes for various categories of participants

\begin{tabular}{|l|r|r|r|r|}
\hline Category & $\begin{array}{r}\text { Population } \\
\left(\boldsymbol{N}_{\boldsymbol{0}}\right)\end{array}$ & $\begin{array}{r}\text { Computed sample } \\
\left(\boldsymbol{n}_{\boldsymbol{0}}\right)\end{array}$ & $\begin{array}{r}\text { Corrected sample } \\
\left(\boldsymbol{n}_{\boldsymbol{i}}\right)\end{array}$ & $\begin{array}{r}\text { Actualised } \\
\text { sample }\end{array}$ \\
\hline ECDE Coordinators & 6 & 2 & 2 & 2 \\
\hline ECDE Teachers & 400 & 159 & 114 & 93 \\
\hline Sub-County Administrators & 6 & 2 & 2 & 2 \\
\hline Ward Administrators & 30 & 12 & 9 & 9 \\
\hline Village Administrators & 143 & 57 & 41 & 39 \\
\hline Total & $\mathbf{5 8 5}$ & $\mathbf{2 3 2}$ & $\mathbf{1 6 6}$ & $\mathbf{1 4 5}$ \\
\hline
\end{tabular}

In addition, qualitative data were obtained through KIIs with 12 participants, including senior officers of the education department, non-governmental agencies and head teachers of primary schools hosting ECDE centres. Primary data were sourced in February 2017. A standard self-reporting survey questionnaire was applied to source quantitative data from participants indicated in Table 1. The Table further shows that of 166 questionnaires that were issued out, $145(87.3 \%)$ were successfully completed and returned. While two modules of KII Guides were applied to source data from senior officers of the education department, non-governmental agencies and head teachers of primary schools hosting the centres.

The instruments were pretested on 15 ECDE teachers, 10 village administrators and 5 head teachers of primary schools. In total, the questionnaire was pre-tested on 25 participants, which is about $15 \%$ of the targeted sample size. In this regard, Sheatsley (1983) observes that a sample size of $10 \%$ or more is sufficient to reveal flaws in data collection instruments. The analysis obtained a Content Validity Index (CVI) of about $71 \%$ for the survey questionnaire, which according to Polit and Beck (2006), indicates contents of the questionnaire were valid. In addition, reliability analysis obtained a Spearman-Brown Prophecy Coefficient of 78\%, which according to Garson (2009), suggests that information sourced by the questionnaire over time was consistent.

Based on the philosophical foundation of the study, both quantitative and qualitative techniques were applied to process and analyse data. In this regard, quantitative analysis techniques included cross-tabulations with Chi square statistic $\left(\chi^{2}\right)$, which was used to determine statistical association between perceived improvement in the status of infrastructural facilities and extent of increase in enrolment over the preceding three years of devolution. In addition, Spearman's Rank Correlation Coefficient was applied to confirm the correlation between perceived improvement in the status of infrastructural facilities and extent of increase in enrolment over the preceding 3 years of devolution. Quantitative analyses were performed using the Statistical Package for Social Sciences (SPSS) and Microsoft Excel. In addition, qualitative data were transcribed and analysed using Nvivo 10, to identify emerging themes and patterns.

Lastly, the study was conducted within the framework of research ethics, in which case, potential participants were consented, given opportunity for voluntary participation, and withdrawal of consent before or during data collection. Participants were also assured about confidentiality of information sourced. In addition, ethical clearance was obtained from the 
University of Nairobi Ethics and Research Committee, while a research permit was obtained from the National Commission for Science, Technology, and Innovation.

\section{Results}

The results presented in this section are organised under two thematic areas, including bivariate analysis of participants' attributes and extent to which enrolment had increased over the preceding three years of devolution, namely, 2013/14, 2014/15 and 2015/16; bivariate analysis of improvement in the status of infrastructural facilities and extent to which enrolment had increased over the reference period. For starters, participants were required to indicate their most honest views regarding the extent to which ECDE enrolment had increased over the said period on a five-point Likert scale, calibrated as 'very great extent', 'great extent', 'moderate extent', 'small extent' and 'not at all'. Whereas ECDE teachers were asked to base their judgment on experiences of their centres, coordinators and administrators were required to focus on experiences of centres in their areas of jurisdiction.

The results show that of the 145 participants, 17 (11.7\%) indicated that enrolment had increased to a 'very great extent', $40(27.6 \%)$ said that enrolment had increased to a 'great extent', $24(16.6 \%)$ rated the increment as 'moderate', $53(36.6 \%)$ indicated that it had increased to a 'small extent', while $11(7.6 \%)$ felt that enrolment had not increased at all. For the convenience of data management, views describing the extent of increment in enrolment as 'very great' and 'great' were merged into one category designated as 'great extent', while views describing the extent of increment as 'moderate' and 'small' were fused into the category designated as 'small extent'. Based on this, cumulative results show that of the 145 participants, 57 (39.3\%) indicated that enrolment had increased to a great extent, $77(53.1 \%)$ said it had increased to a small extent, while 11 (7.6\%) hinted that enrolment had not increased at all. This result was cross-tabulated with participants' attributes, and correlated with perceived improvement in the status of infrastructural facilities. Details are presented under the following sub-sections.

\section{Bivariate analysis of participants' attributes and extent of increase in ECDE enrolment}

The study sourced information on various attributes of participants, including gender, job category, sub-county of residence and highest education level. The analysis involved cross-tabulation of the attributes against extent to which enrolment had increased over the preceding three years of devolution. The results presented in Table 2 show that participants consisted of $96(66.2 \%)$ men and $49(33.8 \%)$ women. Those who felt that enrolment had increased to a great extent (57) included 33 (57.9\%) men and 24 (42.1\%) women. Men also formed the majority of those who perceived that enrolment had increased to a small extent (77) and those who hinted that it had not increased at all (11). For instance, 54 (70.1\%) men against 23 (29.9\%) women rated the increment in enrolment as small. The analysis obtained a computed Chi square $\left(\chi^{2}\right)$ value of 3.488, with 2 degrees of freedom (df) and a $\rho$-value of 0.175 , which suggests lack of a significant association between participants' gender and extent to which enrolment had increased. This implies that there was no significant variation in how male and female participants perceived the extent to which enrolment had increased over the reference period. 
Table 2. Cross-tabulation of participants' attributes and extent of increase in enrolment

\begin{tabular}{|c|c|c|c|c|c|c|c|c|c|c|c|}
\hline \multirow{3}{*}{ Participants attributes } & \multicolumn{8}{|c|}{ Extent to which ECDE enrolment has improved } & \multirow{2}{*}{\multicolumn{3}{|c|}{$\begin{array}{c}\text { Summary of Chi square } \\
\text { results }\end{array}$}} \\
\hline & \multicolumn{2}{|c|}{ Great extent } & \multicolumn{2}{|c|}{ Small extent } & \multicolumn{2}{|c|}{ Not at all } & \multicolumn{2}{|c|}{ Total } & & & \\
\hline & Freq & $\%$ & Freq & $\%$ & Freq & $\%$ & Freq & $\%$ & $\chi^{2}$ & $d f$ & $\rho$-value \\
\hline \multicolumn{12}{|l|}{ Gender } \\
\hline Male & 33 & 57.9 & 54 & 70.1 & 9 & 81.8 & 96 & 66.2 & & & \\
\hline Female & 24 & 42.1 & 23 & 29.9 & 2 & 18.2 & 49 & 33.8 & 3.488 & 2 & 0.175 \\
\hline Total & 57 & 100.0 & 77 & 100.0 & 11 & 100.0 & 145 & 100.0 & & & \\
\hline \multicolumn{12}{|l|}{ Job category } \\
\hline ECDE coordinators & 2 & 3.5 & 0 & 0.0 & 0 & 0.0 & 2 & 1.4 & & & \\
\hline ECDE teachers & 44 & 77.2 & 45 & 58.4 & 3 & 27.3 & 92 & 63.4 & & & \\
\hline Sub-county administrators & 2 & 3.5 & 0 & 0.0 & 0 & 0.0 & 2 & 1.4 & 24.258 & 8 & $0.002 * * *$ \\
\hline Ward administrators & 3 & 5.3 & 4 & 5.2 & 2 & 18.2 & 9 & 6.2 & & & \\
\hline Village administrators & 6 & 10.5 & 28 & 36.4 & 6 & 54.5 & 40 & 27.6 & & & \\
\hline Total & 57 & 100.0 & 77 & 100.0 & 11 & 100.0 & 145 & 100.0 & & & \\
\hline \multicolumn{12}{|l|}{ Sub-county of nativity } \\
\hline Ugenya & 13 & 22.8 & 14 & 18.2 & 3 & 27.3 & 30 & 20.7 & & & \\
\hline Ugunja & 3 & 5.3 & 15 & 19.5 & 3 & 27.3 & 21 & 14.5 & & & \\
\hline Alego-Usonga & 17 & 29.8 & 3 & 3.9 & 0 & 0.0 & 20 & 13.8 & & & \\
\hline Gem & 10 & 17.5 & 10 & 13.0 & 2 & 18.2 & 22 & 15.2 & 29.498 & 10 & $0.001 * * *$ \\
\hline Bondo & 7 & 12.3 & 20 & 26.0 & 1 & 9.1 & 28 & 19.3 & & & \\
\hline Rarieda & 7 & 12.3 & 15 & 19.5 & 2 & 18.2 & 24 & 16.6 & & & \\
\hline Total & 57 & 100.0 & 77 & 100.0 & 11 & 100.0 & 145 & 100.0 & & & \\
\hline \multicolumn{12}{|l|}{ Highest education level } \\
\hline Primary & 9 & 15.8 & 8 & 10.4 & 0 & 0.0 & 17 & 11.7 & & & \\
\hline Secondary & 27 & 47.4 & 25 & 32.5 & 0 & 0.0 & 52 & 35.9 & & & \\
\hline College & 17 & 29.8 & 36 & 46.8 & 9 & 81.8 & 62 & 42.8 & 16.231 & 6 & $0.013 * *$ \\
\hline University & 4 & 7.0 & 8 & 10.4 & 2 & 18.2 & 14 & 9.7 & & & \\
\hline Total & 57 & 100.0 & 77 & 100.0 & 11 & 100.0 & 145 & 100.0 & & & \\
\hline
\end{tabular}

$*, * *, * * *$ show significance at $\rho<0.1, \rho<0.05$ and $\rho<0.01$ error margins, respectively

The results in Table 2 also show that participants consisted of 2 (1.4\%) coordinators, 92 (63.4\%) teachers, and $2(1.4 \%)$ sub-county administrators; others included ward and village administrators, at $9(6.2 \%)$ and $40(27.6 \%)$, respectively. Among those who felt that enrolment had increased to a large extent (57), 44 (77.2\%) were teachers, while $6(10.5 \%)$ were village administrators. Teachers also dominated among those who indicated that enrolment had increased to a small extent (77), with 45 (58.4\%) saying so. Those who indicated that enrolment had not increased at all (11), consisted of $6(54.5 \%)$ village administrators and $3(27.3 \%)$ teachers. The analysis obtained a computed $\chi^{2}$ of 24.258 , with 8 degrees of freedom and a $\rho$-value of 0.002 ; suggesting up to $99 \%$ chance that participants' job 
category significantly associated with perceived extent to which enrolment had increased. This implies that views held by participants of various job categories regarding extent to which enrolment had increased, varied significantly.

Regarding sub-county of nativity, Table 2 shows that 30 (20.7\%) participants were natives of Ugunja, 28 (19.3\%) lived in Bondo, while 24 (16.6\%) resided in Rarieda. Those who perceived that enrolment had increased to a great extent (57) included 17 (29.8\%) natives of Alego-Usonga and 13 (22.8\%) residents of Ugenya. The group that felt enrolment had increased to a small extent (77), included 20 (26.0\%) participants in Bondo, 15 (19.5\%) in Ugunja and another $15(19.5 \%)$ in Rarieda. Those who perceived that enrolment had not increased at all (11) included $3(27.3 \%)$ natives of Ugenya and Ugunja, each. The analysis revealed a significant association between sub-county of nativity and perceived extent to which enrolment had increased $\left(\chi^{2}=29.498, \mathrm{df}=10 \& \rho\right.$-value $\left.=0.001\right)$. The results imply that perceptions regarding the extent to which enrolment had increased varied significantly across the six sub-counties.

The study sourced information regarding participants' educational attainment, in which regard, Table 2 shows that $62(42.8 \%)$ participants had attained college education, 52 (35.9\%) indicated secondary school education, while $14(9.7 \%)$ had attained university education. Among those who indicated that enrolment had increased to a great extent (57), 27 (47.4\%) had attained secondary school education, while 17 (29.8\%) indicated college education. Those who perceived that enrolment had increased to a small extent (77), included 36 (45.8\%) participants with college education and 25 (32.5\%) with secondary school education. Notably, up to $9(81.8 \%)$ participants in the group that felt there was no increment at all (11) had college education, while $2(18.2 \%)$ were university graduates. The analysis obtained a computed $\chi^{2}$ value of 16.231 , with 6 degrees of freedom and a $\rho$-value of 0.013 ; suggesting up to $95 \%$ chance that participants' educational attainment significantly associated with perceived extent to which enrolment had increased over the reference period. This implies that views regarding the extent to which enrolment had increased varied significantly among participants with various levels of education.

Bivariate analysis of improvement in the status of facilities and increment in enrolment

As indicated in the previous sections, the study focused on five types of infrastructural facilities, namely classrooms, furniture, sanitation, outdoor play equipment and assistive facilities for learners with disability. The facilities were used to formulate hypothetical test statements, against which participants were required to indicate the degree of agreement or disagreement on a five-point Likert scale, calibrated as 'agree strongly', 'agree', 'undecided', 'disagree' and 'disagree strongly'. Firstly, participants were requested to indicate the extent to which they either agreed or disagreed with the statement, asserting that 'The status of ECDE classrooms has improved over the past three years of devolution', considering fundamental attributes, including availability, adequacy, quality, suitability and safety. The results presented in Table 3 show that of the 145 participants, 48 (33.1\%) disagreed with the statement, while $15(10.3 \%)$ indicated strong disagreement. On the opposite side of the scale, $57(39.3 \%)$ participants agreed with the statement, while 16 (11.0\%) agreed strongly. 
Cumulatively, about one-half of participants, 73 (50.3\%), expressed agreement with the test statement because they believed that the status of classrooms had improved over the reference period. Contrastingly, 63 (43.4\%) indicated disagreement with the test statement; thus, suggesting the status of classrooms had not improved.

In relation to ECDE enrolment, the results in Table 3 show that among those who felt that enrolment had increased to a great extent (57), 34 (59.6\%) participants agreed with the test statement, while $6(10.5 \%)$ disagreed. Those who felt that enrolment had increased to a small extent (77), included $36(46.8 \%)$ participants who disagreed with the test statement, 11 $(14.3 \%)$ who disagreed strongly and $19(24.7 \%)$ who affirmed it. Based on this, the analysis obtained a computed $\chi^{2}$ value of 30.453 with 8 degrees of freedom and a $\rho$-value of 0.000 , which suggests up to $99 \%$ that improvement in the status of classrooms significantly associated with the extent of increase in enrolment. Further analysis obtained a Spearman's rank correlation coefficient of 0.441 , with a $\rho$-value of 0.000 , which also suggests up to $99 \%$ chance of a positive and significant correlation between improvement in the status of classrooms and the extent of increase in enrolment over the preceding three years of devolution.

Key informant interviews revealed that during the reference period (2013/14-2015/16), the County Government of Siaya constructed new classrooms in 201 ECDE centres, of which 155 had been completed, while 46 were at various stages of completion. However, key informants noted that the need for new classrooms in the entire county was yet to be fully addressed. Construction of classrooms was critical for improving availability, adequacy, quality, suitability and safety of such facilities for ECDE children, which in turn, motivated parents to enrolment their children. In this regard, key informants indicated that enrolment in public ECDE centres had increased significantly from 38,067 learners in the 2012/13 financial year to about 46,258 learners in the 2015/16 financial year. In some centres, enrolment had already exceeded the capacity of new facilities, going by the National Service Standards Guidelines (GoK, 2006b). More specifically, some centres have registered as high as 130 learners, which exceed minimum standards for classrooms, teacher-child ratio and toilet-child ratio, among others (GoK, 2006b). Key informants pointed out that the increasing enrolment was skewed in favour of newly established centres; thereby, leading to severe under-enrolment in pre-existing older centres. Inter-centre migration was motivated by the desire of parents to have their children enjoy learning in safer, cleaner as well as more spacious and suitable classrooms.

Secondly, participants were asked to indicate the degree of agreement or disagreement with the hypothetical test item, stating that 'The status of ECDE furniture has improved over the past three years of devolution'. In this regard, Table 3 shows that of the 145 participants, 58 $(40.0 \%)$ disagreed with the test statement, while $25(17.2 \%)$ disagreed strongly. On the other side of the scale, $49(33.8 \%)$ participants agreed with the statement, while $10(6.9 \%)$ agreed strongly. Cumulatively, 83 (57.2\%) participants expressed disagreement, while 59 (40.7\%) affirmed that the status of furniture had improved. In relation to the extent of increase in enrolment, the results in Table 3 show that among those who felt that enrolment had increased to a great extent (57), 23 (40.4\%) participants agreed that the status of furniture had 
improved over the reference period, while 20 (35.1\%) disagreed. Among those who believed that enrolment had increased to a small extent (77), 33 (42.9\%) participants felt that the statement was untrue, while $26(33.8 \%)$ affirmed it.

Based on this, the analysis obtained a computed $\chi^{2}$ value of 25.938 , with 8 degrees of freedom and a $\rho$-value of 0.001 , which suggests up to $99 \%$ chance that improvement in the status of furniture significantly associated with the extent of increase in enrolment over the reference period. More still, the analysis obtained a Spearman's rank correlation coefficient of 0.351 , with a $\rho$-value of 0.000 , which again suggests up to $99 \%$ chance that there was a significant positive correlation between improvement in the status of furniture and the extent to which enrolment had increased. This implies that as the status of furniture improved, enrolment levels increased proportionately.

Key informant interviews revealed that the County Government was continuously furnishing and equipping new centres. In this regard, key informants indicated that of the 155 completed centres, 66 had been furnished with new desks, chairs, tables and black boards. The initiative improved the status of furniture by improving fundamental qualities such as adequacy, safety and suitability, particularly because they were designed for use by ECDE children. Key informants observed that enrolment level increased faster in furnished than in unfurnished centres. Nonetheless, some informants raised concern regarding the quality of furniture procured by the County Government, as some pieces broke down too soon due to poor workmanship. This challenge influenced participants' view regarding improvement in the status of furniture and the extent to which enrolment increased during the reference period.

Thirdly, participants were requested to indicate the extent of agreement or disagreement with the hypothetical test statement, asserting that 'The status of ECDE sanitation facilities has improved over the past three years of devolution'. The results presented in Table 3 show that about two-thirds of the participants, $86(59.3 \%)$, disagreed with the test statement, while 17 (11.7\%) disagreed strongly. On the opposite side of the scale, 29 (20.0\%) participants agreed with the test statement, while $4(2.8 \%)$ agreed strongly. Cumulatively, the results show that up to $103(71.0 \%)$ participants expressed disagreement with the hypothetical test statement because they felt that sanitation facilities for learners had not improved; while 33 (22.8\%) believed that the statement was true. Among those who felt that enrolment had increased to a great extent (57), up to 35 (61.4\%) disagreed with the test statement, while 10 (17.5\%) agreed. Among those who perceived that enrolment had increased to a small extent (77), 46 (59.7\%) indicated disagreement with the test statement, while 15 (19.5\%) affirmed it. 
Table 3. Improvement in status of infrastructural facilities and extent of increase in enrolment

\begin{tabular}{|c|c|c|c|c|c|c|c|c|c|c|c|}
\hline \multirow{3}{*}{ Aspects of infrastructural facilities } & \multicolumn{8}{|c|}{ Extent to which ECDE enrolment has increased over past 2 yrs } & \multirow{2}{*}{\multicolumn{3}{|c|}{$\begin{array}{l}\text { Summary of Chi } \\
\text { Square results }\end{array}$}} \\
\hline & \multicolumn{2}{|c|}{ Great extent } & \multicolumn{2}{|c|}{ Small extent } & \multicolumn{2}{|c|}{ Not at all } & \multicolumn{2}{|c|}{ Total } & & & \\
\hline & Freq & $\%$ & Freq & $\%$ & Freq & $\%$ & Freq & $\%$ & $\chi^{2}$ & $d f$ & $\rho$-value \\
\hline \multicolumn{12}{|l|}{ Status of ECDE classrooms has improved } \\
\hline Agree strongly & 9 & 15.8 & 6 & 7.8 & 1 & 9.1 & 16 & 11.0 & & & \\
\hline Agree & 34 & 59.6 & 19 & 24.7 & 4 & 36.4 & 57 & 39.3 & & & \\
\hline Undecided & 4 & 7.0 & 5 & 6.5 & 0 & 0.0 & 9 & 6.2 & 30.453 & 8 & $0.000^{* * * *}$ \\
\hline Disagree & 6 & 10.5 & 36 & 46.8 & 6 & 54.5 & 48 & 33.1 & & & \\
\hline Disagree strongly & 4 & 7.0 & 11 & 14.3 & 0 & 0.0 & 15 & 10.3 & & & \\
\hline Total & 57 & 100.0 & 77 & 100.0 & 11 & 100.0 & 145 & 100.0 & & & \\
\hline \multicolumn{12}{|l|}{ Status of ECDE furniture has improved } \\
\hline Agree strongly & 8 & 14.0 & 2 & 2.6 & 0 & 0.0 & 10 & 6.9 & & & \\
\hline Agree & 23 & 40.4 & 26 & 33.8 & 0 & 0.0 & 49 & 33.8 & & & \\
\hline Undecided & 2 & 3.5 & 0 & 0.0 & 1 & 9.1 & 3 & 2.1 & 25.938 & 8 & $0.001^{* * *}$ \\
\hline Disagree & 20 & 35.1 & 33 & 42.9 & 5 & 45.5 & 58 & 40.0 & & & \\
\hline Disagree strongly & 4 & 7.0 & 16 & 20.8 & 5 & 45.5 & 25 & 17.2 & & & \\
\hline Total & 57 & 100.0 & 77 & 100.0 & 11 & 100.0 & 145 & 100.0 & & & \\
\hline \multicolumn{12}{|c|}{ Status of ECDE sanitation facilities has improved } \\
\hline Agree strongly & 2 & 3.5 & 2 & 2.6 & 0 & 0.0 & 4 & 2.8 & & & \\
\hline Agree & 10 & 17.5 & 15 & 19.5 & 4 & 36.4 & 29 & 20.0 & & & \\
\hline Undecided & 4 & 7.0 & 4 & 5.2 & 1 & 9.1 & 9 & 6.2 & 3.057 & 8 & 0.931 \\
\hline Disagree & 35 & 61.4 & 46 & 59.7 & 5 & 45.5 & 86 & 59.3 & & & \\
\hline Disagree strongly & 6 & 10.5 & 10 & 13.0 & 1 & 9.1 & 17 & 11.7 & & & \\
\hline Total & 57 & 100.0 & 77 & 100.0 & 11 & 100.0 & 145 & 100.0 & & & \\
\hline \multicolumn{12}{|c|}{ Status of ECDE outdoor play equipment has improved } \\
\hline Agree strongly & 0 & 0.0 & 0 & 0.0 & 0 & 0.0 & 0 & 0.0 & & & \\
\hline Agree & 4 & 7.0 & 6 & 7.8 & 1 & 9.1 & 11 & 7.6 & & & \\
\hline Undecided & 12 & 21.1 & 14 & 18.2 & 1 & 9.1 & 27 & 18.6 & 1.609 & 6 & 0.925 \\
\hline Disagree & 24 & 42.1 & 33 & 42.9 & 4 & 36.4 & 61 & 42.1 & & & \\
\hline Disagree strongly & 17 & 29.8 & 24 & 31.2 & 5 & 45.5 & 46 & 31.7 & & & \\
\hline Total & 57 & 100.0 & 77 & 100.0 & 11 & 100.0 & 145 & 100.0 & & & \\
\hline \multicolumn{12}{|c|}{ Status of ECDE assistive facilities for disabled leaders has improved } \\
\hline Agree strongly & 0 & 0.0 & 0 & 0.0 & 0 & 0.0 & 0 & 0.0 & & & \\
\hline Agree & 3 & 5.3 & 3 & 3.9 & 1 & 9.1 & 7 & 4.8 & & & \\
\hline Undecided & 3 & 5.3 & 3 & 3.9 & 1 & 9.1 & 7 & 4.8 & 2.840 & 6 & 0.829 \\
\hline Disagree & 18 & 31.6 & 30 & 39.0 & 2 & 18.2 & 50 & 34.5 & & & \\
\hline Disagree strongly & 33 & 57.9 & 41 & 53.2 & 7 & 63.6 & 81 & 55.9 & & & \\
\hline Total & 57 & 100.0 & 77 & 100.0 & 11 & 100.0 & 145 & 100.0 & & & \\
\hline
\end{tabular}

$*, * *, * * *$ show significance at $\rho<0.1, \rho<0.05$ and $\rho<0.01$ error margins, respectively 
Based on this, the analysis obtained a computed $\chi^{2}$ value of 3.057, with 8 degrees of freedom and a $\rho$-value of 0.931 , which suggests lack of a significant association between improvement in the status of sanitation facilities and the extent of increase in enrolment. Furthermore, the analysis obtained a Spearman's rank correlation coefficient of -0.030 , with a $\rho$-value of 0.721 , which confirms lack of a significant correlation between improvement in the status of sanitation facilities and the extent of increase in enrolment. Key informants attributed the discordance to lack of specific interventions for improving availability, adequacy and suitability of sanitation facilities. Besides, key informants pointed out that establishment of suitable sanitation facilities was not factored in the design of, and budgetary allocation for the construction of new ECDE centres. As a result, more than $70 \%$ of 'completed' centres did not have toilets of their own for children and teachers, as specified by section 7 of the National Service Standard Guidelines (GoK, 2006b). Such centres coped by sharing toilets with host primary schools, albeit with a couple of challenges. In this regard, most host primary schools did not have adequate toilet facilities for their own pupils; hence, the addition of ECDE children intensified pressure on the few available facilities. Besides, most ECDE children had not fully developed toilet use and safety skills; thus, sharing toilets with older pupils presented hygiene-related health hazards. Such challenges influenced parents' decisions regarding enrolment of their children in public centres. Consequently, enrolment was relatively higher in centres with suitable sanitation facilities than in those with poor or no facilities.

Fourthly, the study examined views regarding improvement in the status of outdoor play equipment. In this regard, participants were requested to indicate the degree to which they either agreed or disagreed with the hypothetical test statement, asserting that 'The status of outdoor play equipment has improved over the past three years of devolution'. The results presented in Table 3 show that of the 145 participants, $61(42.1 \%)$ disagreed with the hypothetical test statement, while 46 (31.7\%) disagreed strongly. Contrastingly, $11(7.6 \%)$ participants affirmed the test statement, while $27(18.6 \%)$ were undecided. Cumulative results further show that up to $107(73.8 \%)$ participants failed to affirm the test statement because they believed it was untrue, only $11(7.6 \%)$ participants expressed agreement that the status of outdoor play equipment had improved over the reference period.

The results in Table 3 further show that among those who perceived that enrolment had increased to a great extent (57), 24 (42.1\%) participants disagreed with the test statement, while 17 (29.8\%) disagreed strongly. Among those who felt that enrolment had increased to a small extent, 33 (42.9\%) disagreed, while 24 (31.2\%) disagreed strongly with the statement. A similar pattern of perceptions were expressed by participants who indicated that enrolment had not increased at all. Based on this, the analysis revealed lack of a significant association between improvement in the status of outdoor play equipment and the extent of increase in enrolment over the reference period $\left(\chi^{2}=1.609, \mathrm{df}=6 \& \rho\right.$-value $\left.=0.925\right)$. The analysis also obtained the Spearman's rank correlation coefficient of 0.042 , with a $\rho$-value of 0.612 , which suggests lack of a significant correlation between the duo aspects. This implies that improvement in the status of outdoor play equipment was too small to influence a significant increment in enrolment. 
Key informants attributed the results to lack of specific interventions for improving the status of outdoor play equipment, because establishment of such facilities was not considered in the design of, and budgetary allocation for, the construction of ECDE centres, in line with standards specified by sections 7 and 10 of the National Service Standards Guidelines (GoK, 2006b). As a result, none of the newly established centres had outdoor play equipment of their own, where children could play safely to fulfil physical and cognitive development needs. Even though most centres relied on facilities provided by host primary schools, such were inadequate, outdated, non-functional, unsuitable and unsafe for use by ECDE children. In this regard, key informants underscored that shortage of suitable outdoor play equipment is one factor that influenced parents' choice of private over public ECDE centres.

The study also examined perceptions regarding improvement in the status of assistive facilities for disabled learners. In this regard, participants were requested to indicate the degree of agreement or disagreement with the hypothetical test statement, asserting that 'The status of assistive facilities for children with disability has improved over the past three years of devolution'. The results presented in Table 3 show that of the 145 participants, 81 (55.9\%) disagreed strongly with the test statement, while 50 (34.5\%) disagreed. Contrastingly, only 7 (4.8\%) participants affirmed that status of assistive facilities had improved, while none agreed strongly. Cumulatively, the results show that 131 (90.4\%) participants expressed disagreement with the hypothetical test statement, because they believed that there was no improvement in the status of assistive facilities for learners with disability.

Among those who felt that enrolment had increased to a great extent (57), 33 (57.9\%) disagreed strongly with the test statement, while 18 (31.6\%) disagreed. A similar pattern of perceptions was observed among those who hinted that increase in enrolment was small (77), as well as among those who said there was no increment at all (11). In the latter, for instance, up to $7(63.6 \%)$ participants expressed a strong disagreement with the test statement, while 2 (18.2\%) disagreed. Based on the cross-tabulations, the analysis obtained a computed $\chi^{2}$ value of 2.840 , with 6 degrees of freedom and a $\rho$-value of 0.829 , which suggests lack of a significant association between improvement in the status of assistive facilities for children with disability and the extent of increase in enrolment over the reference period. The analysis also obtained a Spearman's rank correlation coefficient of -0.024 , with a $\rho$-value of 0.777 , which again, suggests lack of a significant correlation between the two aspects. This implies that improvement in the status of such facilities was too small to influence a significant increment in enrolment.

Similarly, key informants noted that there was no improvement in the status of assistive facilities for learners with disability, primarily because such facilities were not considered in the design of, and budgetary allocation for, the establishment of new ECDE centres. Better still, participants observed that the design of such centres and budgetary allocation neglected requirements for the inclusion of children with disability, in terms of assistive facilities for mobility and participation in all learning activities. Key informants further observed that in some centres, steps at the entrance of classrooms were too high for regular children; thus, suggesting that such centres were not ready for the inclusion of children with disability. This situation influenced most parents to keep children with disability at home, contrary to 
requirements of the United Nations' Convention on the Rights of Persons with Disabilities (UNCRPD), which recognises the right of all children with disabilities both to be included in the general education systems and to receive the individual support they require (United Nations, 2006).

\section{Summary and Discussions}

The Kenyan Constitution devolves to county governments the responsibility to design, plan, fund, and deliver quality ECDE services in order to build a solid foundation for human capital and socio-economic development (GoK, 2010; 2013; UNESCO, 2010). The environment in which ECDE is delivered determines the quality, equitability and accessibility of such services by all learners, including those living with disability. An obvious strategy for preparing the ECDE environment for quality, equitable and accessible services is the development of basic infrastructural facilities, such as classrooms, furniture, sanitation, outdoor play equipment and assistive facilities for children with disability (UNESCO, 2010; Garcia \& Neuman, 2010). This study shows that even though one-half of participants, 73 $(50.3 \%)$, affirmed that the status of ECDE classrooms had improved over the preceding three years of devolution; a significant proportion, 63 (43.4\%), indicated lack of improvement. This suggests even though the County Government had constructed suitable and safe classrooms in 201 new ECDE centres, the need for such facilities was yet to be addressed fully. Nevertheless, improvement in the status of classrooms significantly associated with the extent of increase in enrolment $\left(\chi^{2}=30.453, \mathrm{df}=8 \& \rho\right.$-value $\left.=0.000\right)$; which implies that improvement in the status of such facilities contributed significantly to increase in ECDE enrolment over the reference period.

Notably though, the increment skewed in favour of centres with new classrooms; thus, resulting to serious congestion in such centres, and desertion of older centres. Given the importance of ECDE in laying down a strong foundation for lifelong educational attainment, no parent would like his/her child to miss out opportunity for a good start in centres with quality classrooms, which stimulate children's cognitive and social development (NDE, 2010); as well as protect them from elements of weather and soil-related infections, as earlier documented by (Mawere and Muguti 2015; Alexander et al. 2013; and Adukia 2013). The issue of skewed enrolment and its ensuing challenges bring to fore the need for better planning by the County Government to ensure equitable distribution of new classroom facilities in order to minimise cases of congestion and desertion; thereby, ensure optimal utilisation of ECDE resources.

For centres hosted in primary school compounds, not all cases of congestion were due to skewed enrolment; some were attributed to unlawful takeover of ECDE classrooms by head teachers of host primary schools for use by their pupils. The challenge is rooted in a pair of legal predicaments, viz. involvement of head teachers in the management of ECDE activities, even though such mandate is not provided for in the Basic Education Act; and delayed establishment of management boards to run ECDE centres, as per Section 55 (1) of the Act (GoK, 2013). The twin challenges make ECDE facilities highly vulnerable to intrusion by head teachers of host primary schools. Even though solution to the challenge lies in the 
establishment of management boards, the County Government must tread carefully not to disrupt the support provided by host primary schools in terms of teaching and learning materials, kitchen facilities, water, sanitation, and in some cases, teachers. In view of this, the County Government should focus on making ECDE centres self-reliant as a prerequisite for the establishment of management boards.

About two-thirds of participants, 83 (57.2\%), indicated that the status of furniture in ECDE centres had not improved over the three years of devolution; only 59 (40.7\%) affirmed that there was improvement in the status of such facilities. This result is consistent with information sourced from programme reports, which indicated that of the 155 centres where new classrooms were complete, 66 (42.6\%) had received furniture from the County Government, including desks, chairs, tables and cabinets. Besides, improvement in the status of furniture significantly associated with the extent of increase in enrolment over the reference period $\left(\chi^{2}=25.938, \mathrm{df}=8 \& \rho\right.$-value $\left.=0.001\right)$; which implies that improvement in the status of such facilities made a significant contribution to increase in enrolment over the reference period. Improving the status of ECDE furniture is a fundamental requirement for improving quality of the learning environment, which in turn, encourages enrolment and prolongs retention. Chairs and tables of suitable heights enable children to balance their weight when seated; thus, minimising the risk of falling down, as earlier established by (Kang'ethe et al. 2015); while maximising learners' comfort, supporting their physical and cognitive development, as well as reducing the risk of soil-borne health issues, including worm infestation, as reported by (Osho et al. 2014). Consequently, furnishing more centres is likely to increase enrolment further, towards achievement of national and SDG 4 enrolment targets (UNESCO, 2017). However, being a capital intensive undertaking, the County Government should ensure that ECDE furniture is not only adequate, but also of high quality and durability. Involving local administrators in verification of furniture's quality will ensure that the County Government obtains value for resources invested in furnishing ECDE centres.

Majority of the participants, 103 (71.0\%), believed that the status of sanitation facilities had not improved over the preceding three years of devolution; while less than one-third, 33 (22.8\%), indicated improvement in the status of such facilities. This is consistent with the findings, which show that construction of new sanitation facilities was not factored in the design of, and budgetary allocation for ECDE infrastructural facilities. Consequently, no significant association existed between improvement in the status of sanitation facilities and the extent of increase in ECDE enrolment over the reference period $\left(\chi^{2}=3.057\right.$, df $=8 \&$ $\rho$-value $=0.931$ ). This implies that the status of sanitation facilities did not make a significant contribution to increase in enrolment over the reference period. Lack of suitable and safe sanitation facilities undermines ability of the learning environment to deliver quality services, which in turn, frustrates enrolment by discouraging parents from enrolling their children or causing learners to miss school due hygiene-related infections, as was established by (Alexander et al. 2013; Adukia 2013; as well as Van der Gaag and Putcha 2013). Notably, some ECDE centres coped with the challenge by letting their ECDE children share sanitation facilities with older children of host primary schools. However, the practice was faulted for escalating the risk of hygiene-related infections, which affected ECDE children' physical and 
intellectual development, with far-reaching implications on enrolment. Similar observations were made by (Mawere and Muguti 2015 and Chepkonga 2017), among other authors. The risk of infections is aggravated by inadequacy of sanitation facilities in host schools, as well as nascent toilet use and safety skills among ECDE children. Going forward, the County Government should prioritise the issue of sanitation facilities in the design of, and financial plans for developing infrastructural facilities in ECDE centres.

Further, majority of participants, 107 (73.8\%), believed that the status of outdoor play equipment had not improved over the three years of devolution; only less than one-tenth, 11 (7.6\%) affirmed that there was improvement. The results are consistent with the realisation that there was no specific intervention for improving the status of outdoor play equipment in ECDE centres. Consequently, no significant association existed between improvement in the status of outdoor play equipment and the extent of increase in enrolment over the reference period $\left(\chi^{2}=1.609\right.$, df $=6 \& \rho$-value $\left.=0.925\right)$; implying that improvement in the status of outdoor play equipment did not make a significant contribution to increase in enrolment over the same period. The importance of outdoor play equipment to children's physical, cognitive and social development, as documented by (McCarthy and Guiney 2004); (Johnson et al. 2010) and (NDE 2011); needs no further emphasis. However, it's worth underscoring that availability of functional and safe outdoor play equipment is one factor that motivates parents to enrol their children, with anticipation for holistic development. This resonates with the realisation that enrolment was relatively higher in centres with some functional outdoor play equipment than in those with no facilities at all. Notably, in a few pre-existing centres, such facilities were developed with the support of faith-based institutions and development agencies.

Non-improvement in the status of outdoor play equipment is linkable to failure of the County Government to incorporate aspects of such facilities in the design and budgetary allocation for developing ECDE centres. As a result, none of the newly established centres had outdoor play equipment of their own. Most of them coped with the challenge by sharing the facilities used by older children in host primary schools, albeit with challenges such as lack or inadequacy of functional and safe equipment, suited for the age of ECDE children. Another challenge was the high risk of injuries due to lack of safety measures, leading to apprehension among some children. Given that more than $90 \%$ of ECDE centres are hosted in primary schools, the establishment of separate outdoor play equipment for ECDE children, including field and equipment, depends on availability of space and willingness of the school board of management to share part of their land for the said purpose. This will require engagement at higher levels of county and national governments, particularly because within the framework of devolution, ECDE centres are under county governments, while host primary schools are run by the national government. Whatever it takes, this study amplifies the need for all ECDE centres to have outdoor play equipment designed for use by young children; thereby, make ECDE truly holistic and motivate more parents to enrol their children.

Most participants, 131 (90.4\%), said that there was no improvement in the status of assistive facilities for learners with disability. Only 7 (4.8\%) acknowledged that there was some improvement in the status of such facilities. Notably, the County Government did not have 
any plan or budget to design, procure, install or adapt existing facilities to the needs of learners with disability. Consequently, the study found no significant association between improvement in the status of assistive facilities and the extent of increase in ECDE enrolment over the preceding three years of devolution $\left(\chi^{2}=2.840\right.$, df $=6 \& \rho$-value $\left.=0.829\right)$. This implies that improvement in the status of assistive facilities for children with disability did not make a significant contribution to increase in ECDE enrolment over the reference period. The results confirm those published by (Stubbs 2009), who identified lack of appropriate assistive resources as a fundamental factor impeding the enrolment of children with disability, particularly in resource-poor countries. Without assistive facilities, children with disability find it too difficult to overcome structural bottlenecks such as steep stairs, narrow doorways and high door handles, among others (UNESCO, 2010). In view of this, providing assistive facilities is at the centre of making ECDE centres more responsive to the needs of children with disability, which in turn, should motivate enrolment and expand access to education for such children in line with provisions of the UNCRPD. In this regard, the County Government has an obligation of allocating more resources and to prioritise modification of existing facilities, as well as construction or installation of new ones, on a needs-basis, in order to facilitate physical access to crucial facilities such as classrooms and toilets.

\section{Conclusion}

The study focused on determining infrastructural facilities that influence ECDE enrolment within the context of devolution. Its purpose was two-fold: influence County Government's investment decisions in basic ECDE infrastructural facilities in order to increase enrolment; as well as contribute to relevant policy discourses and stimulate research not only in Kenya, but also in other developing countries. Of the five types of infrastructural facilities examined by the study, only classrooms and furniture improved to the extent of causing a significant influence on enrolment during the first three years of devolution, viz. 2013/14, 2014/15 and 2015/16. This was because the County Government's investment plan focused on improving the status of classrooms and furniture, but ignored other important aspects of infrastructure such as sanitation, outdoor play equipment and assistive facilities for learners with disability. Despite the significant relationship between enrolment and improvement in the status of classrooms and furniture, the need to broaden the scope of infrastructural facilities considered in the investment plan is self-obtrusive. It's worth noting that lack of access to suitable and safe sanitation, outdoor play equipment and assistive facilities undermines the ability of ECDE centres to retain learners as well as provide holistic development to children's social, emotional, cognitive, linguistic and physical needs, which according to UNESCO (2010), are collectively essential for building a strong foundation for lifelong educational attainment and socio-economic development.

\section{References}

Adukia, A. (2013). Sanitation and education. Cambridge, MA: Harvard Graduate School of Education.

Alexander, K. T., Dreibelbis, R., Freeman, M. C., Ojeny, B., \& Rheingans. R. (2013). Improving service delivery of water, sanitation, and hygiene in primary schools: a 
cluster-randomized trial in western Kenya. Journal of Water and Health, 11(3), 507-519.

Ashley, D., \& Orenstein, D. M. (2005). Sociological theory: classical statements $\left(6^{\text {th }}\right.$ Ed.). Boston, MA, USA: Pearson Education.

Burgers, L. (2000). Background and rationale for school sanitation and hygiene education. New York: UNICEF.

Chambers, J., Shkolnik, J., \& Pérez, M. (2003). Total expenditures for students with disabilities, 1999-2000: spending variation by disability. Palo Alto: American Institutes for Research, Centre for Special Education Finance.

Chepkonga, M. C. (2017). Influence of learning facilities on provision of quality education in Early Childhood Development Centres in Kenya. International Journal of Education \& Research, 5(6), 15-26.

County Government of Siaya. (2014). The County Integrated Development Plan 2013-2017, Siaya, Kenya.

County Government of Siaya. (2016). Department of Education, Youth Affairs, Gender and Social Services Strategic Plan, 2015/16-2019/20, Siaya, Kenya.

Fink, A. (1995). The Survey Kit: How to Sample in Surveys. Thousand Oaks, CA: Sage Publications.

Gallahue, D. L. (1993). Motor development and movement skill acquisition in early childhood education. In B. Spodek (Ed.), Handbook of Research on the Education of Young Children (pp. 24-76). New York: MacMillan Publishing Company.

Garcia, M., \& Neuman, M. (2010). Early childhood development. New York: African Region Human Development, World Bank

Garson, G. D. (2009). Reliability analysis. Journal of Modern Applied Statistical Methods, 6(1), 21-29.

Government of Kenya. (2006a). Early Childhood Development Policy Framework, Nairobi: Ministry of Education.

Government of Kenya. (2006b). Early Childhood Development Service Standard Guidelines for Kenya, Nairobi: Ministry of Education.

Government of Kenya. (2010). The Constitution of Kenya, Nairobi: Kenya Law Reporting.

Government of Kenya. (2012a). A Policy Framework for Education: Aligning Education and Training to the Constitution of Kenya (2010) and Kenya Vision 2030 and beyond. Nairobi, Ministry of Education.

Government of Kenya. (2012b). The County Governments Act, Nairobi: Kenya Law Reporting. 
Government of Kenya. (2013). The Basic Education Act, 2013, Nairobi: Kenya Law Reporting.

Government of Kenya. (2016). Education Sector Report 2017/18-2019/20. Nairobi: Ministry of Education.

Hughes, J. A., \& Sharrock, W. W. (1997). Philosophy of Social Research (3 ${ }^{\text {rd }}$ ed.). London: Longman

Jasper, C., Le, T., \& Bartram, J. (2012). Water and sanitation in schools: A systematic review of the health and educational outcomes. International Journal of Environmental Resources and Public Health, 9(8), 2772-2787. doi:10.3390/ijerph9082772

Johnson, J., Christie, J., \& Wardle, F. (2010). The Importance of Outdoor Play for Children. Retrieved from: http://www.communityplaythings.com/resources/articles/2010/outdoor-play

Jordanova, T., Cronk, R., Obando, W., Medina, O. Z., Kinoshita, R., \& Bartram, J. (2015). Water, sanitation, and hygiene in schools in low socio-economic regions in Nicaragua: a cross-sectional survey. International Journal of Environmental Resources and Public Health, 12(6), 6197-217.

Kang'ethe, S. N., Wakahiu, J., \& Karanja, M. (2015). Assessment of the Early Childhood Development Policy Implementation in Kenya, Case Study of Ruiru District. Journal or Education and Social Policy, 2(1), 78-89.

Mawere, V. H., \& Muguti, J. (2015). Availability, Adequacy and Suitability of Infrastructure, Furniture and Outdoor Play Area Equipment at ECD in Bindura District, Zimbabwe. Journal of Social Science \& Education, 5(3), 543-551.

Nebraska Department of Education. (2011). Early Childhood Programs: A Guide to Serving Children Birth to Kindergarten Entrance Age. Nebraska: NDE. education.ne.gov/oec/

Osho L. O., Aliyu, N., Okolie, O., \& Onifade, O. (2014). Implementation of Early Childhood Education: A Case Study in Nigeria. Universal Journal of Educational Research, 2(2), 119-125.

Polit, D. E., \& Beck, C. T. (2006) Essentials of Nursing Research, (6 ${ }^{\text {th }}$ ed.). Philadelphia: Lippincott Williams \& Wilkins.

Sale, J. E. M., Lohfeld, L. H., \& Brazil, K. (2002). Revisiting the Quantitative-Qualitative Debate: Implications for Mixed Methods Research. Quality and Quantity, 36(1), 43-53.

Sheatsley, P. B. (1983). Questionnaire Construction and Item Writing. In P. H. Rossi, J. D. Wright, \& A. B. Anderson (Eds.), Handbook of Survey Research. San Diego, CA: Academic Press, Inc. 
Shinali, M., \& Kamau, B. (2016). A critical analysis of county governments' role in financing early childhood development and education programmes: The case of Narok County, Kenya. Educational Research International, 5(1), 87-91.

Stubbs, S. (2009). Inclusive education: where there are few resources? Oslo: Atlas Alliance. Retrieved from http://www.eenet.org.uk/theory_practice/IE\%20few\%20resources\%202008.pdf

UNESCO. (2010). Reaching the marginalized EFA Global Monitoring Report 2010. Paris: UNESCO.

UNESCO. (2017). Unpacking Sustainable Development Goal 4: Education 2030. ED-16/ESC-PCR/GD/1. (REV. Oct. 2017). Paris: Education Sector.

UNICEF. (2008). The state of the World's Children. New York: United Nations Children's Fund.

UNICEF. (2009). Child Friendly Schools Manual. NY: United Nations Children's Fund.

United Nations. (2006). Convention on the Rights of Persons with Disabilities. United Nations, December 6. Retrieved from http://www.un.org/esa/socdev/enable/rights/convtexte.htm Accessed on 3/3/2014

Wanjau, F. G. (2013). Influence of immediate preschool environment on curriculum implementation in public preschools in Mirangine District, Nyandarua County, Kenya. A Research Project Submitted in Partial Fulfilment of the Requirement for the Degree of Master of Education in Early Childhood Education, University of Nairobi.

Wong, P. W. (2014). A Snapshot on qualitative research methods. Educational Research and Reviews, 9(5), 130-140.

World Bank. (2015). Kenya Devolution Working Paper Series: Summary Overview. Washington, DC: World Bank Group.

\section{Copyright Disclaimer}

Copyright reserved by the author(s).

This article is an open-access article distributed under the terms and conditions of the Creative Commons Attribution license (http://creativecommons.org/licenses/by/3.0/). 